\title{
Insights into the physicochemical properties of the Malaysian oil palm leaves as an alternative source of industrial materials and bioenergy
}

\author{
Emmanuel Onoja ${ }^{a, b}$, Nursyafreena Attan ${ }^{a}$ Sheela Chandren ${ }^{a}$, Fazira llyana Abdul Razak ${ }^{a}$, Aemi \\ Syazwani Abdul Keyon ${ }^{\mathrm{a}}$, Naji Arafat Mahat ${ }^{\mathrm{a}}$, Roswanira Abdul Wahab ${ }^{\mathrm{a},}$ \\ ${ }^{a}$ Department of Chemistry, Faculty of Science, Universiti Teknologi Malaysia, 81310, UTM Johor Bahru, Johor, Malaysia. \\ ${ }^{b}$ Department of Science Laboratory Technology, The Federal Polytechnic, Kaura Namoda, P.M.B. 1012, Zamfara State, Nigeria. \\ *Corresponding author: roswanira@kimia.fs.utm.my
}

\section{Article history}

Received 27 April 2017

Accepted 17 November 2017

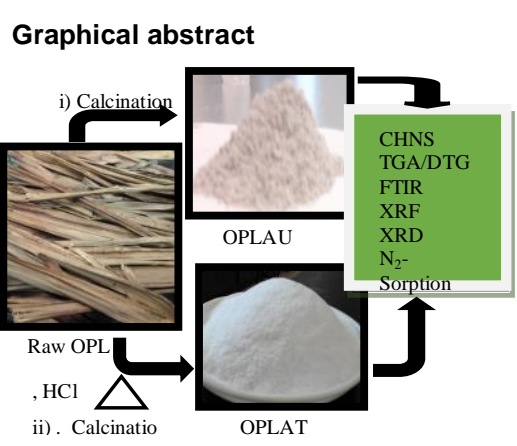

\begin{abstract}
This work was aimed at providing a comprehensive physicochemical characterization of the Malaysian oil palm leaves (OPL) that may be useful for industrial applications as well as giving new insights on minimizing the environmental impact of oil palm biomass. The leaves of discarded oil palm fronds were collected, dried and ground. The leaves powder was subjected to acid and thermal treatments prior to physicochemical analyses. Physicochemical characterization included analyses of thermal gravimetry, ultimate analysis, Fourier-transform infrared spectroscopy, X-ray fluorescence, Xray diffraction and nitrogen sorption. Ultimate analysis revealed that the untreated OPL contained carbon $(46.98 \%)$, hydrogen $(6.500 \%)$, nitrogen $(1.810 \%)$ and sulphur $(0.150 \%)$ with a moderately high calorific value of $19.21 \mathrm{MJ} / \mathrm{kg}$. Thermal gravimetric and differential thermal gravimetric analyses indicated that $\mathrm{OPL}$ is a lignocellulosic material with little moisture and ash contents. X-ray Florescence revealed $\mathrm{Ca}(39.20 \%), \mathrm{K}(22.10 \%)$ and $\mathrm{Si}(19.20 \%)$ as the three major elements in the ash of the untreated sample with $\mathrm{Si}(95.20 \%)$ being predominant for the treated ones, resulting from the leaching of alkali and alkaline earth metals. The ash of the acid treated sample was majorly amorphous silica that was slightly mesoporous with a surface area of $160.59 \mathrm{~m}^{2} \mathrm{~g}^{-1}$ as shown by X-ray diffraction and nitrogen sorption analyses, respectively. These findings confirmed that the Malaysian OPL biomass is a good source of amorphous silica following treatment with acid. The OPL may prove useful as a potential renewable source of bioenergy and an alternative silica source for industrial applications.
\end{abstract}

Keywords: Physicochemical, oil palm leaves, silica, sustainable, bioenergy.

\section{INTRODUCTION}

The economy of Malaysian government has been positively enhanced by the oil palm industry, as Malaysia is known to be one of the world's major exporter of palm oil and its associated products [1, 2]. The growth rate of oil palm plantations in Malaysia over the years has been steady and rapid, with the total oil palm plantations that was approximately 54000 hectares in the 1960s [3], increased to about 5.39 million hectares in 2014 [4]. However, the large-scale plantations of this commercially important oil palm tree is one of the major contributors to the environmental problems following the generation of large amounts of biomass wastes, estimated over 190 million tonness in 2015 [5]. In fact, the extracted palm oil only accounts for approximately $10 \%$ of the oil palm fresh fruit bunch (OPFFB), while the remaining $90 \%$ are biomass, treated as waste in most cases [6].These biomass includes oil palm trunk (OPT), oil palm fronds (OPF), oil palm empty fruit bunches (OPEFB), palm kernel shells (PKS), palm oil mill effluents (POME) and oil palm mesocarp fibers (OPMF) [5]. OPF are produced in large quantities during pruning, harvesting and replanting season, making it readily available, accessible and renewable, which to a large extent is greatly underutilized [2]. A matter of fact, about 47 million tons of dry weight oil palm fronds (OPF) are produced annually during harvesting of OPFFB [5], with additional 3.7 million tons of dry OPF cut down and allowed to decompose naturally during the season of replanting.

While insignificant percentage of oil palm biomass have been converted to value-added products (adsorbents, fillers and anti-caking) by various conversion processes such as mechanical [7] and thermochemical [8], the full economic benefits of OPL remains unexploited. Certain parts of oil palm biomass wastes are useful in their natural forms, while others may require chemical or thermochemical processes to be converted into commercially valuable end products. For instance, the OPEFB and OPF undergo chemithermomechanical pulping, forming small sized pulps and crushed oil palm fruit shells are converted into briquettes and used as fuel [9]. While OPF are pelleted for feeding live stocks [10] and probably a good source of hydrogen gas [8], the majority of OPF are decomposed either artificially or naturally by microorganisms in the plantations for soil mulching. These methods are not only aesthetically displeasing but also impede the movement of heavy machinery or vehicles during harvesting season [11].

Considering that the oil palm biomass in general and OPF in particular are underutilized at the industrial level [11], the development of scientific approaches capitalizing on producing value 
added products from such inexpensive resources may prove useful. Comprehensive studies on the physicochemical characterization of OPL may prove pertinent in realizing such a goal. While several studies of partial characterization of OPF have been reported [12, 13], their focus was mostly on proximate analyses and extraction alone. However, the comprehensive studies on the physicochemical properties of OPL for suggesting possible industrial applications remains unreported. In view of such importance as well as echoing to the philosophy of Malaysian "Zero Waste Initiatives", the present research that aimed at providing a comprehensive physicochemical characterization of the Malaysian OPL that may be useful for industrial applications as well as providing new insights on minimizing the environmental impact of oil palm biomass wastes acquires significance. The study believes that the work proposed here may prove beneficial in revealing the hidden potentials of OPL which will help in converting it into value-added materials as well as providing an alternative use for this readily available OPL.

\section{EXPERIMENTAL}

\section{Sample collection and treatment}

Freshly harvested OPF were collected from an oil palm plantation at Universiti Tecknologi, Malaysia (UTM). The OPL were detached from the petiole and manually sorted out to remove unwanted materials such as sand and dirt. The sorted OPL were cut into sizable pieces $(\sim 10 \mathrm{~cm}$ in length), washed with tap water and rinsed with ultrapure water. The cleaned OPL were dried in an oven at $80{ }^{\circ} \mathrm{C}$ for $72 \mathrm{~h}$. The dried OPL were ground into powder with a laboratory blender and stored in polyethylene bags at room temperature for further use.

\section{Acid treatment of OPL}

The OPL powder was divided into two samples, with one of the samples being used unmodified while the second sample was subjected to acid treatment. In this work, OPL powder $(50.0 \mathrm{~g})$ was dispersed in $1.0 \mathrm{M} \mathrm{HCl}(250 \mathrm{~mL})$ and heated in an oil bath equipped with magnetic stirrer. The dispersed solution was heated to a temperature of $100{ }^{\circ} \mathrm{C}$ and allowed to stir at $400 \mathrm{rpm}$ for $2 \mathrm{~h}$. The dispersion was allowed to cool at ambient temperature, and the supernatant was decanted. The wet dispersed powder was washed several times with ultrapure water until a neutral $\mathrm{pH}$ was obtained. The dispersed powder was filtered and dried in an oven at a temperature of $80^{\circ} \mathrm{C}$ for $24 \mathrm{~h}$.

\section{Thermal treatment of the samples}

Both untreated (OPL) and treated (OPLT) samples were subjected to thermal treatment using a Nabertherm (R; Germany) furnace. Each sample $(25.0 \mathrm{~g})$ was placed in silica crucibles and calcined in a preheated furnace at $600{ }^{\circ} \mathrm{C}$ for $9 \mathrm{~h}$. The ash resulting from the thermal treatment were collected and labelled as oil palm leaves ash untreated (OPLAU) and oil palm leaves ash treated (OPLAT). These ashes were separately stored in capped vials at room temperature for further analysis.

\section{Physicochemical characterization}

The raw OPL, OPLT and their ashes (OPLAU and OPLAT) were characterized using the spectrometric techniques described below. Two samples comprising OPL and OPLT were subjected to ultimate and proximate analyses, while their ashes (OPLAU and OPLAT) were analysed using X-ray fluorescence, X-ray diffraction, and nitrogen sorption respectively. All the four samples (OPL, OPLT, OPLAU and OPLAT) were analysed for various functional groups, using Fourier transform infrared spectroscopy. Details of each analysis is presented in the following sections.

\section{Thermal gravimetric analysis}

Thermal gravimetric analysis (TGA) and differential thermal gravimetric (DTG) analysis of OPL and OPLT powder were carried out using a Thermogravimetric Analyzer Q500-2164 (Perkin Elmer,
USA) at a heating rate of $5{ }^{\circ} \mathrm{C} / \mathrm{min}$ within a temperature range of 30 ${ }^{\circ} \mathrm{C}$ to $1000{ }^{\circ} \mathrm{C}$ under nitrogen atmosphere.

\section{Ultimate analysis}

The ultimate analysis of the untreated OPL and OPLT were carried out to determine the elemental composition of Malaysian OPL as well as the effect of acid treatment on OPL composition. Carbon, hydrogen, nitrogen and sulphur content of OPL and OPLT powder were determined using a CHNS Elementar analyzer (VarioMICRO Cube V3 - 15135057; Germany).

\section{Fourier transform infrared spectroscopy (FTIR)}

Samples of raw OPL, OPLT, OPLAU and OPLAT were subjected to FTIR analysis. Each sample $(1.0 \mathrm{mg})$ was thoroughly ground in 100 $\mathrm{mg}$ of potassium bromide $(\mathrm{KBr})$, and the spectra were recorded in transmission mode from 400 and $4000 \mathrm{~cm}^{-1}$ using a Perkin Elmer spectrophotometer (Frontier 2000; USA) with a resolution of $4 \mathrm{~cm}^{-1}$.

\section{X-ray fluorescence (XRF)}

OPLAU and OPLAT were scanned in an Energy Disperse X-Ray Fluorescence instrument (EDXRF: Rigaku NEX CG; Japan) operating under helium gas flowing at $0.6 \mathrm{~L} / \mathrm{min}$. This was done to determine the weight percent of the various metallic and non-metallic oxides present in the samples. The total elemental analysis was also carried out on OPLAU to determine the various elements present in the natural Malaysian OPL.

\section{X-ray diffraction (XRD)}

The crystallographic structure of OPLAU and OPLAT was analysed for the presence of silica and its related compounds using a SmartLab X-Ray Diffractometer (Rigaku; Japan) with $\mathrm{Cu} \mathrm{K \alpha}$ radiation of wavelength $(\lambda) 1.5406 \AA$, filtered electronically using a

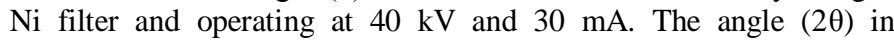
reflection mode was scanned at $2^{\circ}$ per min.

\section{Nitrogen sorption}

The analysis to determine the surface area, pore volume and pore size of OPLAU and OPLAT was performed using a Nitrogen-sorption (Micromeritics 3Flex 3.01; USA) instrument. The sample $(0.1484 \mathrm{~g})$ was first degassed at $90{ }^{\circ} \mathrm{C}$ for $1 \mathrm{~h}$ followed by subsequent degassing at $300{ }^{\circ} \mathrm{C}$ for $4 \mathrm{~h}$ at a ramp rate of $10{ }^{\circ} \mathrm{C} / \mathrm{min}$. The tube containing the sample was placed on the analysis port of the instrument, and the analysis was carried out at a bath temperature of $77 \mathrm{~K}$.

\section{RESULTS AND DISCUSSION}

\section{Optimizing the production of $\mathrm{SiO}_{2}$ by acid treatment}

Alkali and alkaline earth metals (AAEMs) exist partly as oxides, oxalates, carbonates and chloride salts in cells and pores of biomass after drying or they could be ionically bound to hemicellulose and lignin. Removal of AAEMs from biomass cells, therefore depends on mass transfer within the biomass pores [14]. The extent to which AAEMs are leached out of biomass is a function of the particles size. Hence, grinding the sample to smaller particle sizes enhances the leaching process by exposing more surface area of the biomass to the leaching agent, to achieve the desired result within the shortest time possible. It has been reported that the concentration of some monovalent AAEMs, such as $\mathrm{Na}$ and $\mathrm{K}$, can be reduced by approximately $80 \%$ when the biomass is leached with demineralized water. On the other hand, this process can sufficiently leach just about $20 \%$ of divalent AAEMs like $\mathrm{Ca}$ and $\mathrm{Mg}$ [14]. In this study, OPL was washed with demineralized water, dried and pulverized into a powder form. The OPL powder was treated with $\mathrm{HCl}(1 \mathrm{M})$ for $2 \mathrm{~h}$ as described in the function block diagram (Fig. 1). The leached AAEMs in form of soluble chloride salts were removed from the dispersed powder by rinsing several times with deionized water. This is to ensure that AAEMs that may be retained in OPL pores after the acid treatment, were completely removed prior to calcination. In order to maximize the $\mathrm{SiO}_{2}$ content of OPLAT, the choice of acid is important. Chakraverty and his co-researchers [15] reported that using $\mathrm{H}_{2} \mathrm{SO}_{4}$ as 
leaching agent could lead to formation of metallic sulphates, some of which are insoluble in water, hence are not easily removed during rinsing. Therefore, the study used $\mathrm{HCl}$ as the leaching agent to circumvent the drawback associated with the use of $\mathrm{H}_{2} \mathrm{SO}_{4}$. Diluted $\mathrm{HCl}$ was sufficient for the leaching process, in accordance with previous report citing the that employment of highly concentrated $\mathrm{HCl}$ has no appreciable effect on the amount of leached AAEMs [15]. It is worth mentioning here that to optimize $\mathrm{SiO}_{2}$ production during calcination, heating at a moderate temperature is required to synthesize $\mathrm{SiO}_{2}$ rich ash. This is because subjecting biomass to a very high temperature could lead to fusion of $\mathrm{SiO}_{2}$ product as the organic matters are being removed [16]. The heating rate is also an important parameter to be considered, as heating at a low rate produces ash with low concentration of AAEMs [17]. Hence, a heating rate of $1 \% \mathrm{~min}$ was employed with the furnace temperature maintained at $600{ }^{\circ} \mathrm{C}$.

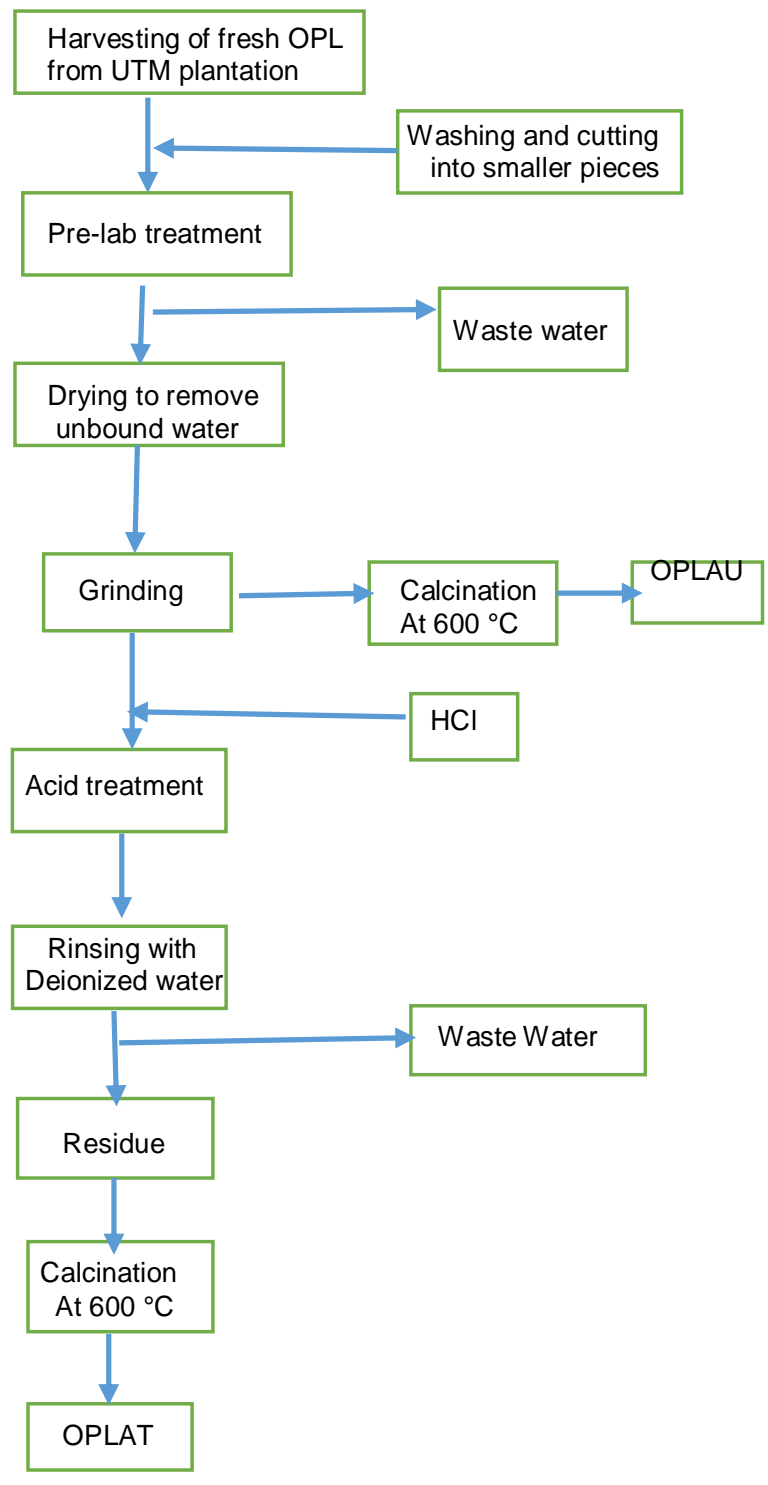

Fig. 1 Function block diagram for producing OPLAU and OPLAT

\section{Ultimate and proximate analysis}

Ultimate analysis was carried out to determine the mass percentages of carbon, hydrogen, nitrogen and sulfur (CHNS) present in the OPL [18] and OPLT. The information on the mass percentage of CHNS could prove useful for determining the fuel properties [19] of OPL. The results of ultimate and proximate analyses of OPL are presented in Tables 1a and b, respectively. The high values of carbon, hydrogen and oxygen accounts for the high volatile matter as presented in the proximate analysis. Carbon and hydrogen were oxidized to $\mathrm{CO}_{2}$ and $\mathrm{H}_{2} \mathrm{O}$ during combustion. The values of carbon and hydrogen from the ultimate analysis were used to estimate the calorific value (the measure of the total energy content) of OPL [20]. Calorific value is the amount of heat that would be released from a fuel when it undergoes combustion. The highest heating value (HHV) of OPL and OPLT were calculated to be 19.21 and $17.18 \mathrm{MJ} / \mathrm{kg}$ respectively using the model from Yin [21] as shown by Eq. (1).

$$
H H V=0.2949 C+0.8250 H
$$

Comparing the ultimate and proximate analyses results of OPL and OPLT, it was observed that there was a slight reduction in the percentage weight of carbon, hydrogen, nitrogen and sulphur (Table 1a). A similar trend was also observed for volatile matter and fixed carbon (Table 1b). This could be attributed to the fact that as AAEMs were leached out of OPL during the acid treatment, some of these elements that were chemically bound to AAEMs were equally removed, hence, a corresponding decrease in their percentage composition in OPLT. These observations were consistent with findings reported in literature [22]. Similarly, the calorific value of OPL was slightly reduced by the effect of the leaching acid (Table 1).

Table 1 (a) Ultimate analysis and (b) Proximate analysis of OPL

\begin{tabular}{|c|c|c|}
\hline \multicolumn{3}{|c|}{ a). Ultimate analysis (wt. \% dry basis) } \\
\hline & OPL & OPLT \\
\hline Carbon & 46.9760 & 42.5147 \\
\hline Hydrogen & 6.4953 & 5.6210 \\
\hline Nitrogen & 1.8128 & 1.5311 \\
\hline Sulphur & 0.1481 & 0.1026 \\
\hline Oxygen* & 44.5678 & 50.2306 \\
\hline \multicolumn{3}{|c|}{ b). Proximate analysis (wt. \% dry basis) } \\
\hline & OPL & OPLT \\
\hline Moisture content & 4.9000 & 6.1000 \\
\hline Volatile matter & 67.8000 & 64.4000 \\
\hline Ash & 5.4000 & 10.6000 \\
\hline Fixed carbon* & 21.9000 & 18.9000 \\
\hline HHV (MJ/kg) & 19.2118 & 17.1749 \\
\hline
\end{tabular}

*Determined by difference

\section{Thermogravimetric analysis (TGA)}

TGA was carried out on raw OPL and OPLT to establish their chemical compositions. The raw OPL and OPLT powder were subjected to thermal treatment, and the results were as shown in Table 1, Fig. 2a and $2 \mathrm{~b}$ respectively. From Table 1 , it can be seen that the Malaysian OPL have high contents of volatile matter $(67.80 \%)$, followed by fixed carbon $(21.90 \%)$, moisture $(4.90 \%)$ and ash $(5.40 \%)$ contents. Such a high volatile matter content in the Malaysian OPL accounts for its relatively high calorific value which is consistent with results of earlier researchers [23, 24]. A weight loss was observed between $50{ }^{\circ} \mathrm{C}$ and $160{ }^{\circ} \mathrm{C}$ (Fig. 2a) which is attributed to the evaporation of water molecules. From this profile (Fig. 2a), it can be observed that thermal decomposition started at $\sim 180^{\circ} \mathrm{C}$ due to the combustion of volatile matter that led to the production of $\mathrm{CO}_{2}$ and water vapor. A drastic decrease in weight was obtained between 310 ${ }^{\circ} \mathrm{C}$ and $360{ }^{\circ} \mathrm{C}$, (Fig. 2a) corresponding to decomposition of hemicellulose and cellulose. This decrease gradually came to an end at approximately $460{ }^{\circ} \mathrm{C}$, beyond which the decrease was relatively slower until the final temperature evaluated $\left(1000^{\circ} \mathrm{C}\right)$.

The DTG profile for raw OPL (Fig. 2a) displayed two overlapping peaks and a tailing section. The lower temperature peak $\left(\sim 250{ }^{\circ} \mathrm{C}\right)$ was attributed to the decomposition of hemicellulose, while the higher temperature peak $\left(\sim 310{ }^{\circ} \mathrm{C}\right)$ corresponds to decomposition of cellulose. Similar to the finding by Liyanage and co-worker [25], in this present research too, the start of the flat tailing section was observed at $\sim 360{ }^{\circ} \mathrm{C}$, assigned to the decomposition of lignin and the progression continued up to $500{ }^{\circ} \mathrm{C}$. Such an observation was similar with that reported by previous researchers [20], indicating that the 
major devolatilization started at approximately $330{ }^{\circ} \mathrm{C}$ through $370{ }^{\circ} \mathrm{C}$ and completed at about $460^{\circ}$
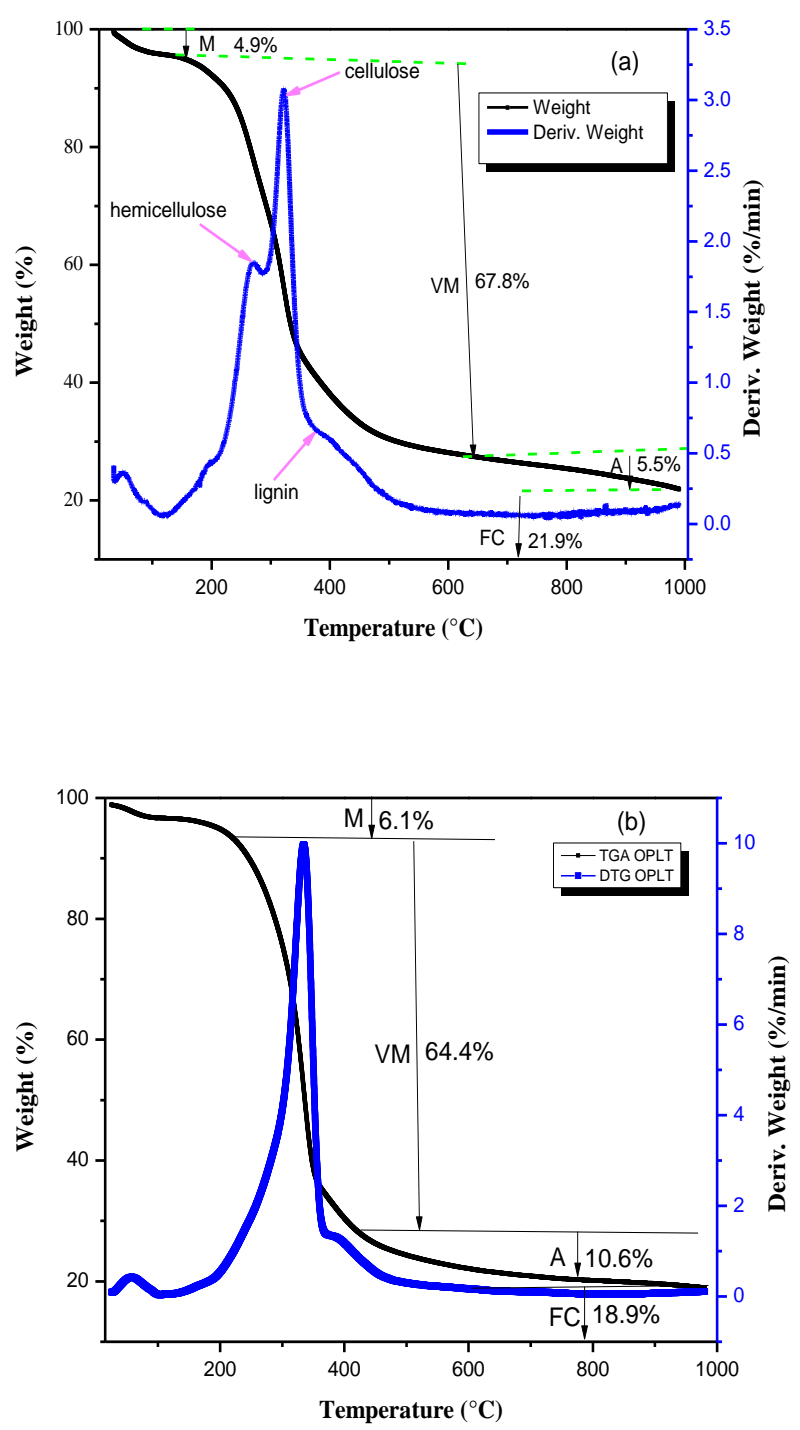

Fig. 2 TGA-DTG curves for (a) raw OPL, (b) OPLT

The thermal gravimetric profile for the untreated Malaysian OPL (Fig. 2a) generated here further supported our initial finding of its high calorific value $(19.21 \mathrm{MJ} / \mathrm{kg})$. Therefore, the fact that the Malaysian OPL consisted mostly of lignocellulosic biomass could not be ruled out. Considering that Malaysia is one of the largest producers of oil palm biomass, having its processed by-products 7 times higher than that of natural timber [26], and because the biomass waste of OPF constituted about $58 \%$ of the total oil palm biomass wastes [5], its utilization for producing hydrogen gas as well as other biofuels [27] may prove to be a feasible option for future commercial and household energy use. While it has been estimated that the energy demand for Malaysia would reach 100 million tonness of oil equivalent by 2030 [28] and since oil is a depleting non-renewable source of energy, pursuing specific researches on utilizing oil palm biomass as a potential clean energy source for electricity deserve consideration.

The TGA-DTG curve for OPLT (Fig. 2b) displayed a slightly different profile from that of raw OPL (Fig. 2a). From the DTG profile (Fig. 2b), it was observed that the exothermic peak that occurred at approximately $250{ }^{\circ} \mathrm{C}$ assigned to hemicellulose had completely disapperaed leaving a strong exothermic peak at $335^{\circ} \mathrm{C}$. It is worth noting that the tailing section attributed to lignin in raw OPL
(Fig. 2a) had considerably reduced in OPLT (Fig. 2b). This was associated to the effect of acid on the lignocellulosic composition of OPL which may have either completely removed or lowered the concentration of hemicellulose and ligin in OPL [29]. This findings clearly affirmed that the acid treatment of OPL affects the chemical composition of OPL as earlier observed in the immediate preceeding section. Our results corroborated the findings of earlier researchers [30]

\section{Acid treatment/XRF analysis}

The overall aim of the acid treatment in this work is to improve the quality of the silica $\left(\mathrm{SiO}_{2}\right)$ contained in the ash so that it can serve as a good alternative source of silica that is more cost effective than conventional sources. Subjecting the raw OPL to acid treatment also reduced the concentration of some metals, especially the AAEMs [31]. In this work, $\mathrm{HCl}$ was used because it was better than other mineral acids, such as nitric acid $\left(\mathrm{HNO}_{3}\right)$ and sulfuric acid $\left(\mathrm{H}_{2} \mathrm{SO}_{4}\right)$, at removing or reducing the concentrations of metallic elements present in biomass [32]. The appearances of dried OPL, OPLAU and OPLAT are shown in Fig. 3a, 3b and 3c respectively. Physical observation of these ashes showed that while OPLAU (Fig. 3b) is grayish in color, OPLAT (Fig. 3c) is whitish. The color differences were attributed to the high concentration of some AAEMs $(\mathrm{Ca}, \mathrm{K}$ and $\mathrm{Mg})$ present in OPLAU. The concentrations of these metals were considerably reduced during the acid leaching process as shown by XRF analysis in Table 2. The results obtained in this work were in close agreement with those of Matori and coworkers [31]. From Table 2, it can be seen that the six major elements present in OPLAU were $\mathrm{Na}, \mathrm{Mg}, \mathrm{Ca}, \mathrm{K}, \mathrm{Si}$ and $\mathrm{P}$ with $\mathrm{Ca}$ and $\mathrm{K}$ in the highest proportion. On the other hand, XRF analysis of OPLAT showed a drastic reduction in the concentrations of the metallic elements, especially the AAEMs, and a corresponding increase in the concentration of $\mathrm{SiO}_{2}$. The low value of $\mathrm{SiO}_{2}$ in OPLAU may be attributed to the oxidation of silica by $\mathrm{K}^{+}$ during combustion. This was reflected by the corresponding increase in the concentration of $\mathrm{SiO}_{2}$ in OPLAT $(95.30 \%)$ as the treatment considerably reduced the level of $\mathrm{K}^{+}$.
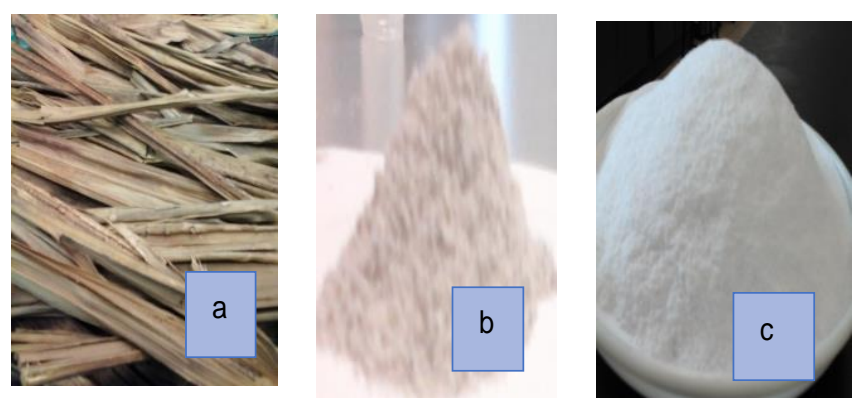

Fig. 3 (a) Dried OPL (b) OPLAU (c) OPLAT.

The results of total elemental analysis of OPLAU (Table 3) indicated that the major elements present in the untreated ash were the six mentioned above with oxygen being the highest $(50.3 \%)$. The others present were in trace amounts. However, elements such as $\mathrm{V}$, $\mathrm{Co}, \mathrm{Ga}, \mathrm{Ge}, \mathrm{Se}, \mathrm{Y}, \mathrm{Nb}, \mathrm{Mo}, \mathrm{Ru}, \mathrm{Rh}, \mathrm{Pd}, \mathrm{Ag}, \mathrm{Cd}, \mathrm{In}, \mathrm{Sb}, \mathrm{Te}, \mathrm{I}, \mathrm{Cs}, \mathrm{Ba}$, La, Ce, Pr, Nd, W, Ir, Pt, Hg, Tl, Bi, Th, Sc, Tc, Rn, Ar, Xe, At, Po, $\mathrm{Lu}, \mathrm{Er}, \mathrm{Ho}, \mathrm{Dy}, \mathrm{Gd}, \mathrm{Sm}, \mathrm{Pm} \mathrm{Pa}$ and Ac were completely absent. This is an indication that the ash of the Malaysian OPL does not contain any radioactive elements, which makes it safe to handle both in the laboratory and in industry. 
Table 2 XRF analysis of OPLAU and OPLAT

\begin{tabular}{ccc}
\hline Compounds & OPLAU & OPLAT \\
\hline $\mathrm{O}$ & 0.000 & 0.000 \\
$\mathrm{Na}_{2} \mathrm{O}$ & $4.860 \pm 0.315$ & $0.657 \pm 0.120$ \\
$\mathrm{MgO}$ & $7.000 \pm 0.081$ & $0.255 \pm 0.016$ \\
$\mathrm{CaO}$ & $39.200 \pm 0.064$ & $0.331 \pm 0.005$ \\
$\mathrm{~K}_{2} \mathrm{O}$ & $22.100 \pm 0.047$ & $0.758 \pm 0.009$ \\
$\mathrm{TiO}_{2}$ & $0.011 \pm 0.001$ & $0.031 \pm 0.001$ \\
$\mathrm{MnO}$ & $0.141 \pm 0.003$ & $0.005 \pm 0.001$ \\
$\mathrm{Fe}_{2} \mathrm{O}_{3}$ & $0.442 \pm 0.005$ & $0.096 \pm 0.001$ \\
$\mathrm{Al}_{2} \mathrm{O}_{3}$ & $0.571 \pm 0.014$ & $0.799 \pm 0.014$ \\
$\mathrm{SiO}_{2}$ & $19.500 \pm 0.049$ & $95.300 \pm 1.200$ \\
$\mathrm{P}_{2} \mathrm{O}_{5}$ & $4.210 \pm 0.011$ & $1.720 \pm 0.009$ \\
$\mathrm{ZnO}$ & $0.082 \pm 0.001$ & $0.017 \pm 0.001$ \\
$\mathrm{SO}$ & $1.850 \pm 0.007$ & $0.035 \pm 0.001$ \\
$\mathrm{PbO}$ & $0.002 \pm 0.002$ & $0.001 \pm 0.001$ \\
\hline
\end{tabular}

\section{Fourier transform infrared (FTIR) spectroscopy}

The FTIR spectra of raw OPL, OPLT, OPLAU and OPLAT are displayed in Fig. 4a, b, c and d, respectively showing several peaks corresponding to different functional groups. For the raw OPL (Fig. 4a) and OPLT powder (Fig. 4b), the broad and intense band in the region of $3382-3431 \mathrm{~cm}^{-1}$ is attributed to $\mathrm{O}-\mathrm{H}$ stretching vibrations arising from intra- and inter-molecular hydrogen bonding due to the presence of cellulose, hemicellulose and lignin [32]. However, the decrease in the intensity of the peak for OPLT (Fig. 4b) suggetst that the treatment had, to some extent reduced the concentration of these organic matters. The peaks in the region $2922-2927 \mathrm{~cm}^{-1}$ and 2856 $2862 \mathrm{~cm}^{-1}$ correspond to $-\mathrm{CH}_{2}$ stretching vibrations, while the peak at $1634 \mathrm{~cm}^{-1}$ is attributed to $\mathrm{C}=\mathrm{O}$ stretching vibration arising from carbonyl groups present in lignin and carbonyl conjugated with aromatic rings [33]. The peaks at $1528 \mathrm{~cm}^{-1}$ and $1447 \mathrm{~cm}^{-1}$ in the raw OPL (Fig. 4a) correspond to stretching vibrations of $\mathrm{C}=\mathrm{C}$ from aromatic ring of lignin $[34,35]$. It was observed that the intensities of these peaks were considerably reduced in OPLT (Fig. 4b), which could be attributed to partial removal of lignin [34]. The peak at 1380 $\mathrm{cm}^{-1}$ (Fig. 4a) is assigned to $\mathrm{C}-\mathrm{H}$ asymmetric deformation, while the peak at $1246 \mathrm{~cm}^{-1}$ is associated with the $\mathrm{C}-\mathrm{H}, \mathrm{O}-\mathrm{H}$ and $-\mathrm{CH}_{2}$ bending vibrations of cellulose [34]. A reduction in the intensities of these peaks was noticed in OPLT (Fig. 4b), indicative that the acid treatment had reduced the quantity of cellulose to an extent. The band at $1083 \mathrm{~cm}^{-1}$ (Fig. 4a) on the other hand can be attributed to $\mathrm{C}-\mathrm{O}, \mathrm{C}=\mathrm{C}$ and $\mathrm{C}-\mathrm{C}-\mathrm{O}$ stretching vibrations from cellulose, hemicellulose and lignin [36]. A slight decrease in the intensity of this peak was also observed for OPLT. It could be infered from the observations above, that subjecting raw OPL to acid treatment had led to reduction in the lignocellulosic composition of OPL, as treating OPL with acid had resulted in degradation and dissolution of the hemicellulose and lignin content of OPL to a considerable level. This was clearly shown by the reduction in the intensities of the peaks within the range of $1200 \mathrm{~cm}^{-1}$ to $1550 \mathrm{~cm}^{-1}$. It is worth pointing out that the FTIR results here agreed well with the TGA-DTG data described earlier for both OPL and OPLT. These observations also corroborated earlier findings by Sim and co-workers [29].

The FTIR spectra of OPLAU (Fig. 4c) and OPLAT (Fig. 4d) showed similar trends. The ash is majorly made up of $\mathrm{SiO}_{2}$; therefore, the prominent peaks indicated here were typical of $\mathrm{SiO}_{2}$. The broad peaks at $3452 \mathrm{~cm}^{-1}$ and $3448 \mathrm{~cm}^{-1}$ for OPLAU (Fig. 4c) and OPLAT (Fig. 4d) are attributed to $-\mathrm{OH}$ stretching vibrations arising from silanol or trapped water molecules, whereas the less prominent peaks at $1638 \mathrm{~cm}^{-1}$ and $1637 \mathrm{~cm}^{-1}$ were assigned to $-\mathrm{OH}$ bending vibrations originating from trapped water molecules. The peaks at $1108 \mathrm{~cm}^{-1}$ and $1132 \mathrm{~cm}^{-1}$ are attributable to vibrations of siloxane ( $\mathrm{Si}-\mathrm{O}-\mathrm{Si}$ ) groups, while the peak at $798 \mathrm{~cm}^{-1}$ and $806 \mathrm{~cm}^{-1}$ in the OPLAU (Fig. 4c) and OPLAT (Fig. 4d) respectively, correspond to stretching vibrations of siloxane (Si-O-Si) bonds. The peaks at $464 \mathrm{~cm}^{-1}$ and $467 \mathrm{~cm}^{-1}$ (Fig. $4 \mathrm{c}$ and $4 \mathrm{~d}$ ) are attributed to the ending vibrations of siloxane ( $\mathrm{Si}-\mathrm{O}-\mathrm{Si}$ ) bonds [37]. However, the two additional peaks observed $1890 \mathrm{~cm}^{-1}$ and $2024 \mathrm{~cm}^{-1}$ for OPLAU (Fig. 4c) could be associated with the presence of additional functional groups in OPLAU sample.

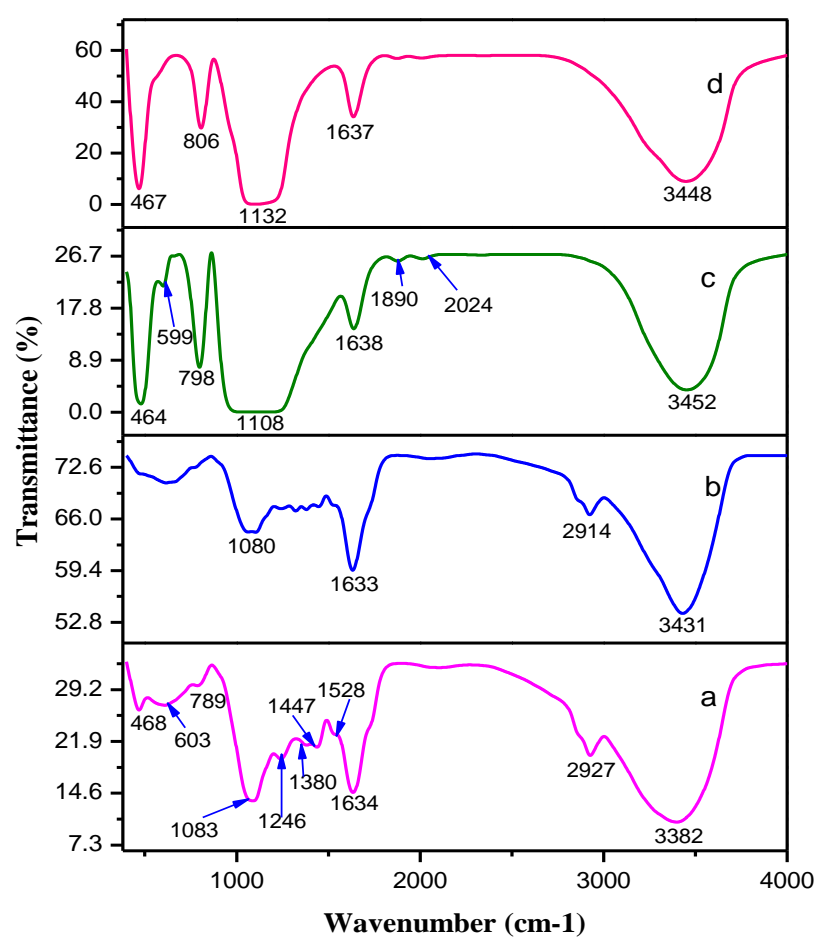

Fig. 4 FTIR analysis of (a) OPL, (b) OPLT, (c) OPLAU, (d) OPLAT

\section{X-ray diffraction}

The XRD patterns for OPLAU and OPLAT are shown in Fig. 5. Both samples were qualitatively analysed for peak identification using the International Centre for Diffraction Data (ICDD) software. From the diffractogram of OPLAU (Fig. 5a), four major mineral phases were identified in addition to amorphous materials present in the sample. These include; minehillite $\left[\mathrm{K}_{3} \mathrm{Ca}_{28} \mathrm{Zn}_{4} \mathrm{Al}_{4} \mathrm{Si}_{40} \mathrm{O}_{112}(\mathrm{OH})_{16}\right]$, cristobalite $\left(\mathrm{SiO}_{2}\right)$, hematite $\left(\mathrm{Fe}_{2} \mathrm{O}_{3}\right)$ and schaferite $\left[\mathrm{NaCa}_{2} \mathrm{Mg}_{2}\left(\mathrm{VO}_{4}\right)_{3}\right.$ with ICDD card numbers 00-038-0371, 01-080-3756, 01-080-5411 and 00-051-1556 respectively. The result is similar to the findings of Koukouzasa and co-workers [38].

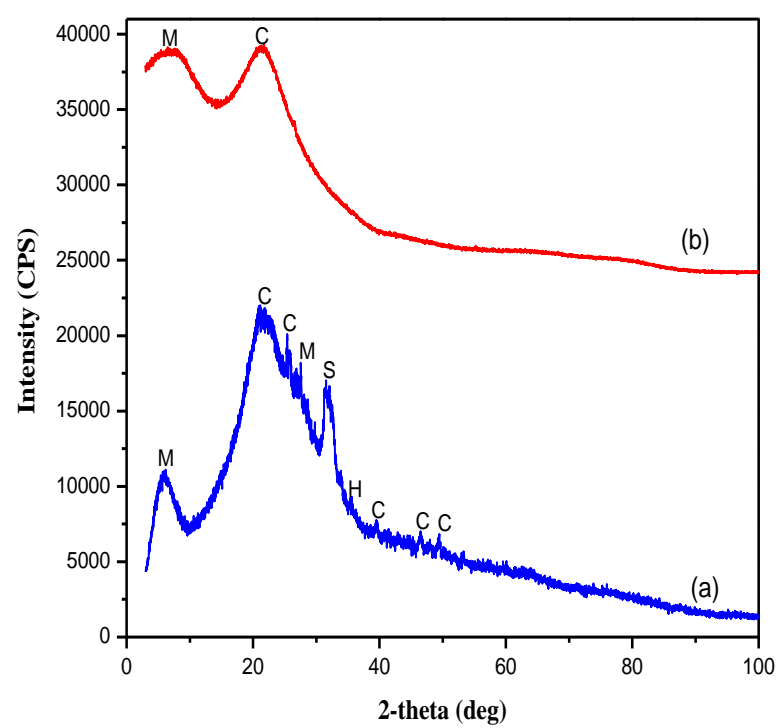

Fig. 5 XRD patterns for (a) OPLAU, (b) OPLAT; showing peaks for major mineral phases in the samples: $\mathrm{H}=$ hematite, $\mathrm{M}=$ minehillite, $\mathrm{C}=$ cristobalite, $\mathrm{S}$ = schaferite. 
It was, however, observed that after subjecting OPL to acid treatment before calcination, the peaks corresponding to hematite and the schaferite had completely disappeared, while the peak for minehillite had reduced to a minimal level (Fig. 5b). The broadness of minehillite peak and the complete disappearance of the peaks assigned to hematite and schaferite in OPLAT (Fig. 5b) is attributed to the reduction in the concentrations of the AAEMs that constitute these minerals. The major component of OPLAT (Fig. 5b) was $\mathrm{SiO}_{2}$ as shown by the band corresponding to $\mathrm{SiO}_{2}$. This complemented the result obtained from the XRF analysis (Table 2). The silica in OPLAT was amorphous in nature, producing a broad band at $2 \theta=21.6^{\circ}$. Music and co-workers [39] published results for amorphous silica obtained from calcined agricultural biomass with equivalent Bragg angles at $2 \theta=22^{\circ}$ and $21.8^{\circ}$, respectively. The result obtained for OPLAT in this work was quite similar to theirs. Subjecting raw OPL to acid treatment before calcination had resulted in the removal of AAEMs to a considerable extent with a corresponding improvement in the quality and quantity of $\mathrm{SiO}_{2}$.

Table 3 Total elemental analysis of OPLAU

\begin{tabular}{cc}
\hline Elements & Mass $(\%)$ \\
\hline $\mathrm{Mg}$ & $4.1700 \pm 0.0453$ \\
$\mathrm{Al}$ & $0.2550 \pm 0.0070$ \\
$\mathrm{Si}$ & $9.2000 \pm 0.0192$ \\
$\mathrm{P}$ & $7.7600 \pm 0.0048$ \\
$\mathrm{~S}$ & $0.7000 \pm 0.0030$ \\
$\mathrm{Cl}$ & $3.6200 \pm 0.0043$ \\
$\mathrm{~K}$ & $12.6000 \pm 0.0337$ \\
$\mathrm{Ca}$ & $13.2000 \pm 0.0331$ \\
$\mathrm{Ti}$ & $0.0094 \pm 0.0006$ \\
$\mathrm{Cr}$ & $0.0310 \pm 0.0006$ \\
$\mathrm{Mn}$ & $0.0389 \pm 0.0016$ \\
$\mathrm{Fe}$ & $0.0762 \pm 0.0020$ \\
$\mathrm{Ni}$ & $0.0089 \pm 0.0004$ \\
$\mathrm{Cu}$ & $0.0700 \pm 0.0009$ \\
$\mathrm{Zn}$ & $0.0449 \pm 0.0006$ \\
$\mathrm{As}$ & $0.0003 \pm 0.0001$ \\
$\mathrm{Br}$ & $0.0142 \pm 0.0002$ \\
$\mathrm{Rb}$ & $0.0210 \pm 0.0002$ \\
$\mathrm{Sr}$ & $0.0067 \pm 0.0001$ \\
$\mathrm{Sn}$ & $0.0004 \pm 0.0001$ \\
$\mathrm{Hf}$ & $0.0026 \pm 0.0006$ \\
$\mathrm{Ta}$ & $0.0018 \pm 0.0005$ \\
$\mathrm{Au}$ & $0.0009 \pm 0.0001$ \\
$\mathrm{~Pb}$ & $0.0005 \pm 0.0001$ \\
$\mathrm{U}$ & $0.0011 \pm 0.0002$ \\
$\mathrm{O}$ & 50.3000 \\
$\mathrm{Na}$ & $3.5400 \pm 0.2160$ \\
$\mathrm{Zt}$ & $0.1810 \pm 0.0017$ \\
$\mathrm{Re}$ & $0.0011 \pm 0.0002$ \\
$\mathrm{Os}$ & $0.0008 \pm 0.0002$ \\
$\mathrm{Fr}$ & $0.0017 \pm 0.0004$ \\
$\mathrm{Kr}$ & $0.0023 \pm 0.0001$ \\
$\mathrm{Rn}$ & $0.0008 \pm 0.0002$ \\
$\mathrm{Yb}$ & $0.0024 \pm 0.0006$ \\
$\mathrm{Tm}$ & $0.0114 \pm 0.0010$ \\
$\mathrm{Eu}$ & $0.0207 \pm 0.0022$ \\
\hline & $0.0323 \pm 0.0037$ \\
\hline
\end{tabular}

\section{Nitrogen sorption}

The results for the multipoint surface area, pore volume and pore size for the OPLAU and OPLAT are tabulated in Table 4, while the nitrogen adsorption/desorption isotherms are presented in Fig. 6.
Information obtained from the adsorption and desorption isotherms (Fig. $6 \mathrm{a}$ and $\mathrm{b})$ were used to determine the specific surface area $\left(\mathrm{m}^{2} \mathrm{~g}\right.$ ${ }^{1}$ ), pore volume $\left(\mathrm{m}^{3} \mathrm{~g}^{-1}\right)$ as well as the pore size $(\AA)$, of OPLAU and OPLAT using the Brunauer-Emmett-Teller (BET) and Barrett-JoynerHalenda (BJH) models (Table 4) [40]. The nitrogen isotherm for OPLAU (Fig. 6a) displayed a low nitrogen adsorption capacity, with the desorption taking almost the same pathway as the adsorption. There was no vissible hysteresis loop observed in the low-relative pressure region, indicative of low porosity of OPLAU. At the lowpressure region, the OPLAU isotherm was almost horizontal with a small hysteresis loop appearing towards the tail end as it approaches the saturation vapour pressure. This observation affirmed that OPLAU sample was majorly microporous in nature with narrow pore size distribution[22]. This is further supported by the low BET surface area, pore volume and large pore diameter (Table 4).

On the other hand, it was found that the nitrogen adsorption /desorption isotherm of OPLAT (Fig. 6b) did not perfectly fit into any of the microporous, mesoporous or macroporous IUPAC classifications. However, the adsorption part has a shape similar to a Type II isotherm, except for the formation of a H3-type hysteresis loop, suggesting that the OPLAT is slightly mesoporous. Presence of an early rounded knee-shape (Fig. 6b) suggests the monolayer formation of nitrogen and slightly microporous surface in the sample, supported by a small t-plot micropore area $\left(8.79 \mathrm{~m}^{2} \mathrm{~g}^{-1}\right)$ in Table 4 .

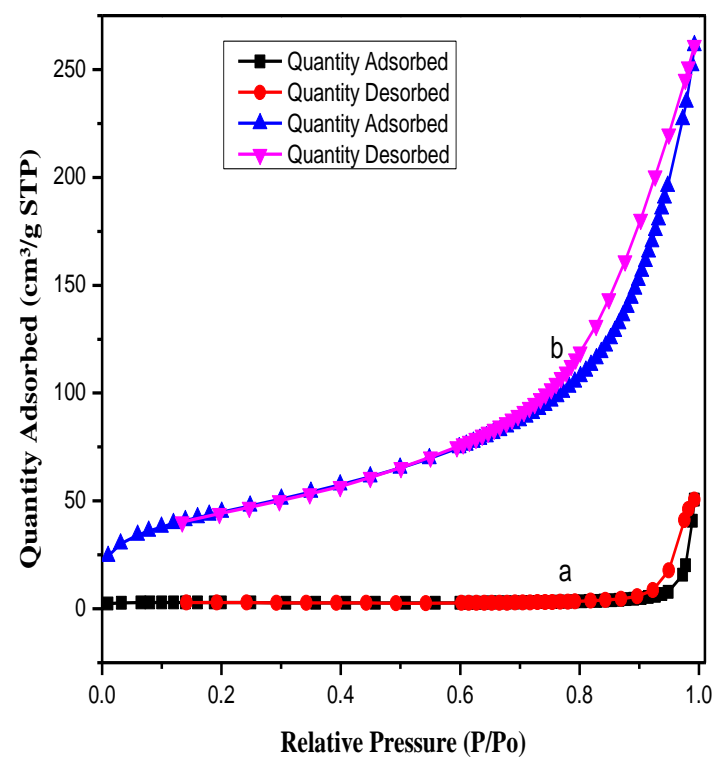

Fig. 6 Nitrogen sorption isotherm: a) OPLAU, b) OPLAT

The low slope region in the middle of the isotherm indicates the occurrence of multilayer adsorption in the first few layers of the sample. Interestingly, the OPLAT (Fig. 6b) isotherm also conforms to Type IV isotherm since it had a H3-type hysteresis loop, suggesting the existence of disordered or lamellar shaped pores. The presence of the hysteresis loop is due to the capillary condensation that occurred in the mesoporous structure during adsorption process, explaining the slightly higher BET surface area $\left(160.59 \mathrm{~m}^{2} \mathrm{~g}^{-1}\right)$. The absence of the usual plateau occurring at higher relative pressure for Type IV isotherms (completely mesoporous materials) further confirmed that OPLAT (Fig. 6b) was not completely mesoporous. This occurrence complements the Type II isotherm which signified that macroporous structures may also be present in the sample. The pore size indicated in Table 4 showed that the sample possessed some mesoporous properties as the adsorption/desorption average pore diameters were $98.3550 \AA$ and $99.9632 \AA$, respectively. In comparison, the exceptionally low BET surface area recorded for OPLAU was attributed to the effect of AAEMs present in raw OPL sample. The differences between the isotherms of OPLAU (Fig. 6a) and OPLAT 
(Fig. 6b) indicates that apart from leaching of AAEMs, the acid treatment also leads to pore opening. The substantial increament in the BET surface area for OPLAT compared to OPLAU is indicative that the acid treatment had distorted the ordered arrangement of the organic matter, which were subsequently broken down during calcination, hence leaving a more porous OPLAT. The much smaller pore volume observed for OPLAU compared to OPLAT (Table 4) follow the trend discused above and could be attributed to the effect of the acid treatment on OPL sample. Howevver, the pore width as well as the pore diameter were conspiscously higher for OPLAU (Table 4). These observations were consistent with findings reported in literature $[17,22]$. It is worth mentioning here that literature on characterization of OPL and its ash is very scanty, therefore, most of the references cited in this study were drawn from study carried out on rice husk.

Table 4 Nitrogen sorption analysis for OPLAU and OPLAT

\begin{tabular}{llll}
\hline Surface Area $\left(\mathbf{m}^{2} / \mathbf{g}\right)$ & OPLAU & OPLAT \\
\hline 1 & Multipoint surface area & 8.419 & 154.994 \\
2 & Brunauer-Emmett-Teller surface area & 12.069 & 160.597 \\
3 & Langmuir surface area & 12.892 & 226.983 \\
4 & t-plot micropore area & 11.193 & 8.798 \\
5 & t-plot external surface area & 0.876 & 151.799 \\
6 & BJH adsorption cumulative surface area & 4.157 & 138.015 \\
7 & BJH desorption cumulative surface area & 7.533 & 146.041
\end{tabular}

Pore Volume $\left(\mathrm{cm}^{3} / \mathrm{g}\right)$

OPLAU OPLAT

1 Multiple point adsorption total pore volume

2 Multiple point desorption total pore volume

3 t-plot micropore volume

4 BJH adsorption cumulative volume pores

5 BJH desorption cumulative volume pores

0.078

\section{Pore Size (̊̊)}

1 Adsorption average pore diameter by BET

\section{OPLAU OPLAT}

2 Desorption average pore diameter by BET

3 BJH adsorption average pore width 416.835

\section{Future potential applications of OPL}

Natural fibers are abundantly available and their specific properties are at par with other fibers used for reinforcement purposes as well as being inexpensive, have a low density and biodegradable [41]. The results of this research revealed the presence of substantial amounts of hemicellulose, cellulose and lignin as well as silica in the OPL biomass that may have significant potential applications in many quarters of industrial setup. It has been indicated that cellulose plays pivotal roles in many chemical applications such as fabrication of high-performance and functional materials, production of biofuel, adsorbents and replacements of petroleum-based plastics. The advent of green technologies focusing on green composites has seen cellulose and lignin components being used for the fabrication of high- performance and functional materials [42] due to their exceptional mechanical properties that can be engineered into robust cellulose micro- and nanofibers for replacing conventional synthetic fibers. These natural nanocomposites can be very useful in the aerospace and military industries [43]. Moreover, natural materials or wastes can also be used as an inexpensive and widely available filler material [41]. The production of thermoplastics reinforced with hydrolyzed pulp fibers to afford cellulose nanocomposites having unusually high modulus and strength values has been reported. In addition, the use of cellulose in biofuel production and as replacement products for petroleum-based plastics due to its renewable, sustainable and carbonneutral properties has also been indicated [43].

The results of this research further found that OPLAT contained high silica contents, which implies that it would be a good alternative source of silica for many industrial applications. Silica and its derivatives have been used as raw materials in the rubber and cosmetics industries mainly as reinforcing agents and in food industries as anti-caking agents. Because the silica in the Malaysian OPL analysed here were found to be amorphous in nature, its potential as a raw material for producing cement and concretes [44] as well as fillers in polymer industries [45] may become significant. Advancements in nanotechnology have successfully led to the production of nanosized silica (silica nanofibers), which are useful as low-loss subwavelength-diameter single mode optical waveguides. As one of the fundamental materials for photonics, silica nanofibers in taper-drawn forms are important in manufacturing nanoscale optical sensors as well as atomic trapping and guiding. Other uses of such nanosized material include as components of microphotonic devices, viz. optical couplers and ring resonators [46]. Furthermore, specialized covalently bound silica macrocyclic ligands have been utilized to separate metal ions such as $\mathrm{Pd}^{+2}, \mathrm{Ag}^{+}$and $\mathrm{Ru}^{+3}$ from nuclear defense wastes, primarily due to the hindrance of such metals ions during the vitrification of confining radionuclides and the fact that they are economically appealing. Likewise, silica has been used as a coating agent for magnetic nanoparticles (MNPs), leading to surface modifications to suit specific applications as well as improvement in the chemical stabilities of MNPs [44]. Silica from OPL can be used for this purpose rather than the expensive conventional silica sources, i.e., tetraethyl orthosilicate (TEOS) and tetramethyl orthosilicate (TMOS).

The depletion in reserves of the world's primary resources from fossil fuels (oil, coal and natural gas) is of a growing concern due to its limited availability and potential adverse effects towards the environment, contributing to global warming and climate change. The ever increasing human populations as well as spurring of economic growths have resulted in significant increase in the consumption of fossil fuels for energy, putting additional pressure on the already depleting natural resources [47]. In view of such limitations, embarking on the use of renewable bioenergy resources such as that from agricultural biomass i.e. oil palm may prove to be imperative. Since the result of this present research revealed that the OPL biomass contained relatively high calorific value $(19.21 \mathrm{MJ} / \mathrm{kg})$, its utilization for cogeneration of bioenergy would supplement the use of conventional energy resources in generating steam and electricity for power boiler, turbine and generator in the oil palm mills. While the heat and power generated from such system may prove to be more than sufficient for use in the oil palm milling process [48], the excess electricity generated by the turbines can subsequently be distributed to the local communities, hence, reducing reliance on fossil fuels for electricity generation. However, the lack of financial supports may limit its application [49] and result in passive partiality towards utilization of energy from oil palm biomass in large palm oil producing countries like Malaysia. It is combination of environmental awareness, financial drivers and governmental policies that provides the incentives to the recovery and secondary utilization of such organic wastes. In this context, the fact that developing new technologies would require substantial amount of investment, from both the government as well as private sectors, concerted efforts for 
materializing such application that could benefit the people at large, prove necessary.

\section{CONCLUSION}

The physicochemical characterization of the OPL revealed high calorific value $(19.21 \mathrm{MJ} / \mathrm{kg})$ for the raw sample, with $\mathrm{SiO}_{2}(95.20 \%)$ being the dominant component of the acid treated sample. The high calorific value of the raw sample may possibly translate into the use of such biomass wastes for clean energy generation, taking into account the ever escalating demand for energy. This study demonstrated that treating OPL with $\mathrm{HCl}$ before calcination had substantially leached out AAEMs and its concentration in the final product (OPLAT) had been reduced considerably, resulting in the production of OPL ash that was quite rich in amorphous $\mathrm{SiO}_{2}$, with relatively large BET surface area compared to the ash from the untreated sample. Therefore, the applications of OPL analysed here as a new source of renewable bioenergy as well as silica, applicable for various industrial applications (pharmaceutical, photonic, optical sensors etc.) merits considerations. Hence, harnessing the full potential of OPL biomass in that context should form an interesting study.

\section{ACKNOWLEDGEMENT}

This work was supported by the Fundamental Research Grant Scheme from the Ministry of Higher Education Malaysia (R.J130000.7826.4F649) and Research University Grant Scheme (Q.J130000.2526.13H09) from the Universiti Teknologi Malaysia, Johor. We would also like to acknowledge valuable help and suggestions provided by our colleagues.

\section{REFERENCES}

[1] Mazaheri, H., Lee, K. T., Bhatia, S., Mohamed, A. R. (2010). Subcritical water liquefaction of oil palm fruit press fiber for the production of biooil: Effect of catalysts. Biores. Technol. 101, 745-751.

[2] Agensi Innovasi Malaysia (AIM), National Biomass Strategy 2020 (2013). New wealth creation for Malaysia's biomass industry: Version 2.0, Agensi Inovasi Malaysia, Kuala Lumpur. Available at: http://etp.pemandu.gov.my/upload/Biomass_Strategy_2013.pdf. Accessed 26 April 2016

[3] Abdullah, N., Sulaiman, F. (2013). The oil palm wastes in Malaysia. In Biomass Now- Sustainable Growth and Use. Intech. 89-92.

[4] Malaysian Palm Oil Board. (2015). Economic and Industry Development Devision. Oil Palm Planted Area Malaysia. Retrieved from http://bepi.mpob.gov.my/index.php/statistics/area.html_Accessed 26 April 2016.

[5] Awalludin, M. F., Sulaiman O., Hashim, R., Wan Nadhari, W. N. A. (2015). An overview of the oil palm industry in Malaysia and its waste utilization through thermochemical conversion, specifically via liquefaction. Renew. Sustain. Ener. Rev. 50, 469-484.

[6] Abdullah, N., Sulaiman, F., Aliasak, Z. (2013). A case study of pyrolysis of oil palm wastes in Malaysia. Proceedings of the 2012 National Physic Conference (PERFIK 2012): AIP Publishing, 331-336.

[7] Abdul Khalil, H. P. S., Nurul Fazita M. R., Bhat A. H., Jawaid M., Nik Fuad N. A. (2010). Development and material properties of new hybrid plywood from oil palm biomass. Mater. Des. 31, 417-424.

[8] Kelly-Yong, T. L., Lee, K. T., Mohamed, A. R., Bhatia, S. (2007) Potential of hydrogen from oil palm biomass as a source of renewable energy worldwide. Ener. Policy 35, 5692-5701.

[9] Chaiyaomporn, K., Chavalparit, O. (2010). Fuel pellets production from biodiesel waste. Environ. Asia 3, 103-110.

[10] Daud, W.R.W., Law, K. N. (2010). Oil palm fibers as papermaking material: Potentials and challenges. Bio. Res. 6, 901-917.

[11] Hashim, R., Sarmin, S. N., Sulaiman, O., Yusof, L. H. M. (2011). Effects of cold setting adhesives on properties of laminated veneer lumber from oil palm trunks in comparison with rubber-wood. Eur. J. Wood. Prod. 69, 53-61.

[12] Rahman, A. A., Abdullah, N., Sulaiman, F. (2014). Temperature effect on the characterization of pyrolysis products from oil palm fronds. Advan. Ener. Eng. 2, 14-21.

[13] Nordin, N. A., Sulaiman, O., Hashim, R., Kassim, M. H. M. (2016). Characterization of different parts of oil palm fronds (Elaeis guineensis) and its properties. Intl. J. Advan. Sci. Eng. Infor. Technol. 6, 74-76.
[14] Oudenhoven, S. R. G., van der Ham, A. G. J., van den Berg, H., Westerhof, R. J. M., Kersten, S. R. A. (2016). Using pyrolytic acid leaching as a pretreatment step in a biomass fast pyrolysis plant: Process design and economic evaluation. Biomass and Bioenergy 95, 388-404.

[15] Chakraverty, A., Mishra, P., Banerjee, H. D. (1988). Investigation of combustion of raw and acid-leached rice husk for production of pure amorphous white silica. J. Mat. Sci. 23, 21-24.

[16] Liu, N., Huo, K., McDowell, M. T., Zhao, J., Yi Cui, Y. (2013). Rice husks as a sustainable source of nanostructured silicon for high performance Li-ion battery anodes. Scientific Report 1-7.

[17] Liou, T.H. (2004). Preparation and characterization of nano-structured silica from rice husk. Mat. Sci. and Eng. A364, 313-323.

[18] Chun-Yang, Y. .(2011) Production of high heating values of biomass from proximate and ultimate analysis. Fuel 90, 1128-1132.

[19] Saidur, R., Abdelaziz, E. A., Demirbas, A., Hossain, M. S., Mekhilef, S. (2011). A review on biomass as a fuel for boilers. Renew. Sustain. Ener. Rev. 15, 2262-2289.

[20] Ghani, W. W. A. K., Abdullah, M. S. F, Matori, K. A., Alias, A. B., da Silva, G. (2010). Physical and thermochemical characterization of Malaysian biomass ashes. J. Ind. Eng. 71(3), 9-17.

[21] Yin, C. Y. (2011). Prediction of higher heating values of biomass from proximate and ultimate analyses. Fuel 90, 1128-1132.

[22] Liou, T. H. (2004). Evolution of chemistry and morphology during the carbonization and combustion of rice husk. Carb. 42, 785-794.

[23] Lim, X. Y., Andresen, J. M. (2011). Pyro-catalytic Deoxgenated Bio-Oil from Palm Oil Empty Fruit Bunch and Fronds with Boric Oxide in a Fixed-Bed Reactor. Fuel Process Technol. 92(9), 1796-1804.

[24] Guangul, F. M., Sulaiman, S. A., Ramli, A. (2012). Gasifier selection, design and gasification of oil palm fronds with preheated and unheated gasifying air. Bioresour Technol. 126: 224-232.

[25] Liyanage, C. D., Pieris, M. (2015). A physico-chemical analysis of coconut shell powder. Procedia Chem. 16, 222-228.

[26] Basiron Y., Chan, K. W. (2004). The oil palm and its sustainability. J. Palm Res. 16, 1-10.

[27] Kalogiannis, K. G., Stefanidis, S., Marianou, A., Michailof, C., Kalogianni, A., Lappas, A. (2015). Lignocellulosic biomass fractionation as a pretreatment step for production of fuels and green chemicals. Waste Biomass Valor 6, 781-790.

[28] Mohamed, M. A A., Salmiaton, A., Wan-Azlina, W. A. K. G., MohamadAmran, M. S., Fakhrul-Razi, A., Taufiq-Yap, Y. H. (2011). Hydrogen rich gas from oil palm biomass as potential source of renewable energy in Malaysia. Renew. Sustain. Ener. Rev. 15, 1258-1270.

[29] Sim, S. F., Mohamed, M., Lu, N. A. L. M. I., Noor Safitri P., Sarman, N. S. P. S., Samsudin, S. N. S. (2012). Computer-assisted analysis of fourier transform infrared (FTIR) spectra for characterization of various treated and untreated agriculture biomass. Bio. Res. 7(4), 5367-5380.

[30] Johan, E., Ogami, K., Matsue, N., Itagaki, Y., Aono, H. (2016). Fabrication of high purity silica from rice husk and its conversion into zsm-5. ARPN J. Eng. and Appl. Sci. 11(6), 4006-4010.

[31] Matori, K. A., Haslinawati, M. M., Wahab, Z. A., Sidek, H. A. A., Ban, T. K., Ghani, W. A. W. A. K. (2009). Producing Amorphous White Silica from Rice Husk. MASAUM J. of Basic and Applied Sciences 1(3), 512 515.

[32] Lionetto, F., Del, Sole, R., Cannoletta, D., Vasapollo, G., Maffezzoli, A. (2012). Monitoring wood degradation during weathering by cellulose crystallinity. Mater. 5, 1910-1922.

[33] Cyran, L. S. (2007). Association and structural diversity of hemicelluloses in the cell walls of rye outer layers: comparison between two ryes with opposite bread making quality. J Agric Food Chem. 55, 2329-2341.

[34] Alemdar, A., Sain, M. (2008). Isolation and characterization of nanofibers from agricultural residues - wheat straw and soy hulls. Bioresour Technol. 99, 1664-1671.

[35] Elias, N., Chandren, S., Attan, N., Mahat, N. A., Razak, F. I. A., Jamalis, J., Wahab, R. A. (2017). Structure and properties of oil palm-based nanocellulose reinforced chitosan nanocomposite for efficient synthesis of butyl butyrate. Carbohyd Poly. 176, 281-292.

[36] Sitti, F. M. R., Sulaiman, O., Hashim, R., Arai, T., Kosugi, A., Abe, H., et al. (2012). Characterization of parenchyma and vascular bundle of oil palm trunk as function of storage time. Lignocellulose 2, 141-148.

[37] Sivasubramanian, S., Sravanthi, K. (2015). Synthesis and characterization of silica nanoparticles from coconut shell. Intl. $J$. Pharma BioSci. 6(1), 530-536.

[38] Koukouzasa, N., Wardb, C. R., Papanikolaoua, D., Lib, Z., Ketikidisa, C. (2009). Quantitative evaluation of minerals in fly ashes of biomass, coal and biomass-coal mixture derived fromcirculating fluidised bed combustion technology. J. of Hazard Mat. 169, 100-107. 
[39] Music, S., Filipovic-Vincekovic, N., Sekovanic, L. (2011). Precipitation of amorphous $\mathrm{SiO}_{2}$ particles and their properties. Braz. J. Chem. Eng. 28(1), 89-94.

[40] Abdelaziz, O. Y., Hulteberg, C. P. (2016). Physicochemical characterization of technical lignins for their potential valorisation. Waste Biomass Valor, 8, 859-869.

[41] Väisänen, T., Haapala, A., Lappaleinen, R., Tomppo, R. (2016) Utilization of agricultural and forest industry waste and residues in natural fibre-polymer composites: A review. Waste Manage. 54, 62-73.

[42] Ashori, A., Nourbakhsh, A. (2010). Bio-based composites from waste agricultural residues. Waste Manage. 30(4), 680-684.

[43] Hinestroza, J., Netravali, A. N. (2014). Cellulose based composites: New Green Nanomaterials. Wiley VCH.

[44] C.D.S., Ghavami, K., Stroeven, P.: Rice husk ash as a supplementary raw material for the production of cellulose-cement composites with improved performance. Waste Biomass Valor. 1, 241-249 (2010)

[45] Arjmandi, R., Hassan, A., Majeed K., Zakaria Z.: Risk husk filled composites. Intl. J. Polym Sci. Article ID 501471 (2015)
[46] Mendez, A., Morse, T. F. (2011). Specialty Optical Fibers Handbook. Massachusetts: Academic Press.

[47] Yatim, P., Mamat, M. N., Mohamad-Zailani, S. H., Ramlee, S. (2016). Energy policy shifts towards sustainable energy future for Malaysia. Clean Technol. Environ. Policy. 18, 1685-1695.

[48] Nasution, M. A., Herawan, T., Rivani, M. (2014). Analysis of palm biomass as electricity from palm oil mills in North Sumatera. Ener. Procedia. 47, 166-172.

[49] Jaafar, M. Z., Wong, H. K., Kamaruddin, N. (2003). Greener energy solutions for a sustainable future: issues and challenges for Malaysia. Ener. Policy. 31, 1061-1072. 